\title{
Comparative Evaluation of the Nutritional, Antinutritional, Functional, and Bioactivity Attributes of Rice Bran Stabilized by Different Heat Treatments
}

\author{
Maria Irakli ${ }^{1, *}$, Athina Lazaridou ${ }^{2} \mathbb{D}$ and Costas G. Biliaderis ${ }^{2}$ \\ 1 Institute of Plant Breeding \& Genetic Resources, Hellenic Agricultural Organization-Demeter, Thermi, \\ 57001 Thessaloniki, Greece \\ 2 Department of Food Science and Technology, School of Agriculture, Aristotle University of Thessaloniki, \\ P.O. Box 235, 54124 Thessaloniki, Greece; athlazar@agro.auth.gr (A.L.); biliader@agro.auth.gr (C.G.B.) \\ * Correspondence: irakli@cerealinstitute.gr; Tel.: +30-231-047-1544
}

Citation: Irakli, M.; Lazaridou, A.; Biliaderis, C.G. Comparative Evaluation of the Nutritional, Antinutritional, Functional, and Bioactivity Attributes of Rice Bran Stabilized by Different Heat Treatments. Foods 2021, 10, 57. https://doi.org/10.3390/ foods 10010057

Received: 7 December 2020 Accepted: 25 December 2020 Published: 28 December 2020

Publisher's Note: MDPI stays neutral with regard to jurisdictional claims in published maps and institutional affiliations.

Copyright: (C) 2020 by the authors. Licensee MDPI, Basel, Switzerland. This article is an open access article distributed under the terms and conditions of the Creative Commons Attribution (CC BY) license (https: / / creativecommons.org/ licenses/by/4.0/).

\begin{abstract}
The objective of this study was to evaluate the effects of different stabilization treatments-namely, dry-heating, infrared-radiation, and microwave-heating-on the nutritional, antinutritional, functional, and bioactivity attributes of rice bran (RB). Among the heating treatments, infrared-radiation exerted the strongest inactivation, resulting in 34.7\% residual lipase activity. All the stabilization methods were found to be effective in the reduction of antinutrients, including phytates, oxalate, saponins, and trypsin inhibitors. No adverse effect of stabilization was noted on chemical composition and fatty acid profile of RB. Instead, stabilization by all heat treatments caused a significant decrease of vitamin $\mathrm{E}$ and total phenolics content in RB; the same trend was observed for the antioxidant activity as evaluated by the DPPH test. The antioxidant activity, as evaluated by ABTS and FRAP tests, and water absorption capacity were improved by the stabilization of RB, whereas the oil absorption capacity and emulsifying properties decreased. Microwave-heating enhanced the foaming properties, whereas infrared-radiation improved the water solubility index and swelling power of RB. Consequently, treatment of RB with infrared-radiation has a potential for industrialization to inactivate the lipase and improve some functional properties of this material for uses as a nutraceutical ingredient in food and cosmetic products.
\end{abstract}

Keywords: rice bran; stabilization; antioxidants; functional properties; bioactives; anti-nutritional components

\section{Introduction}

Rice bran (RB) is an agro-industrial by-product of rice kernel dry milling and consists mainly of the germ, pericarp, aleurone, and sub-aleurone layers [1]. It is a natural source of protein (14-16\%), fat (12-23\%), crude fiber (8-10\%), other carbohydrates, vitamins, minerals, essential unsaturated fatty acids, and antioxidants, such as phenolics, tocopherols, tocotrienols, and $\gamma$-oryzanol with well-known beneficial effects in human health [2]. The predominant bioactive compound in the RB is $\gamma$-oryzanol due to its antioxidant [3], hypocholesterolemic [4], anti-inflammatory [5], anti-cancer [6], and anti-diabetic properties [7]. Furthermore, RB is gaining increased interest in the food, nutraceutical, and pharmaceutical industries, due to its high nutritional value, low cost, easy availability, high bioactivity potential, and the associated health benefits [2].

Despite the presence of various bioactives, the majority of RB is under-utilized as animal feed, fertilizer, or fuel in many developing countries. In Asian countries, it is used successfully for the production of RB oil with many health benefits. The main limitation in food industry applications is the requirement for quick stabilization of the $\mathrm{RB}$, in order to reduce the antinutrients present and deactivate the action of lipase present in the outer layers of rice grain, which is primarily responsible for the hydrolysis of 
triglycerides into glycerol and free fatty acids following the milling process of the rice grains [8]. Immediately after milling, the free fatty acids level is increased, and the RB is unsuitable for human consumption, owing to rancid flavor and soapy taste. Moreover, lipoxygenase and peroxidase also contribute to the rancidity of RB although to a lesser extent [9].

Several stabilization treatments including dry and moist heating [10], extrusion cooking [11], microwave-heating [12,13], infrared-radiation [14,15], ohmic heating [16], parboiling or hydrothermal treatment [17], other physical methods of stabilization or refrigeration [18], enzymatic treatment [19], and chemical methods [20] have been employed immediately after milling to prevent the development of rancidity in RB. The selection of an optimized stabilization method is a crucial point for the food industry in order to ensure high component yield, low cost, and limited loss of bioactive constituents.

As a process, dry-heating is simple, convenient, and amenable to industrialization [21]. On the other hand, microwave-heating and infrared radiation are considered as alternative energy sources with high heat efficiency over shorter processing times without affecting RB quality. Microwave stabilization has been referred to as a quick heating method with high efficiency to inactivate lipase along with a better retention of bioactive compounds [12,22]. Similarly, infrared-radiation constitutes an alternative processing method to achieve efficient drying along with lipase inactivation in RB without affecting its quality $[14,15,23]$. In recent years, infrared-radiation heating has become an important technique in the food processing industry, because of its numerous advantages, such as the low capital cost and low energy cost, the simplicity of the required equipment, a lower drying time, the high quality of dried products, easy control of the process parameters, a uniform temperature distribution, and the clean operational environment, as well as space savings and easy accommodation with convective, conductive, and microwave heating [24]. As for the microwave heating, there are several major drawbacks that limit its application as the sole heating method for the drying process due to the high start-up costs, relatively complicated technology as compared to conventional convection drying despite the shorter drying time, improved product quality, and flexibility [25].

Although the efficiency of the microwave and infrared-radiation heating methods in stabilizing the RB, in relation to nutritional and bioactives profile, has been extensively studied by many researchers, to date, there are no reports dealing systematically with the effects of stabilization methods on functional properties from the technological point of view (physicochemical properties of RB) and their impact on anti-nutritional components. Relevant research works in this respect refer to protein isolates extracted from RB stabilized with different methods [26,27].

Therefore, the present study aimed to investigate the effects of dry-heating, microwave and infrared-radiation heating on the nutritional, antinutritional, and bioactive components of stabilized RB as well as on its functional properties and antioxidant capacities.

\section{Materials and Methods}

\subsection{Sample Preparation}

Fresh RB (10.93\% moisture content) was collected from a local rice mill (Megas Alexandros, Sindos, Thssaloniki, Greece), and it was stabilized immediately using three heating processes as described below: (i) infrared-radiation: RB was transferred in a custom-made device consisting of a shaking aluminum tray, a radiator with two infrared lambs and a connected thermostat, as described by Irakli et al. [15] and it was heated at $140{ }^{\circ} \mathrm{C}$ for $15 \mathrm{~min}$, (ii) dry-heating: RB was spread in thin layers to open pans and then was heated in an oven at $150{ }^{\circ} \mathrm{C}$ for $40 \mathrm{~min}$ and (iii) microwave-heating: RB was moistened up to $21 \%$ and then was placed in a glass plate (spread out in thin layer) and subjected to heating for $2 \mathrm{~min}$ at $650 \mathrm{~W}$, corresponding to an approximately temperature of $160^{\circ} \mathrm{C}$. The stabilized $\mathrm{RB}$ samples were subsequently cooled at ambient temperature, packed in plastic containers, and stored at $4{ }^{\circ} \mathrm{C}$ for further use. An unstabilized RB sample was used as a control 
for comparative purposes, and it was stored under the same conditions as the stabilized RB samples.

\subsection{Color Measurements}

Color was measured using a colorimeter (HunterLab, model MiniScan XE Plus, Reston, VA, USA), following the CIE system defined by the $L^{*}, a^{*}$, and $b^{*}$ coordinates. The total color differences $(\Delta \mathrm{E})$ between the control and stabilized $\mathrm{RB}$ samples were calculated using the equation: $\Delta \mathrm{E}=\left(\Delta \mathrm{L}^{* 2}+\Delta \mathrm{a}^{* 2}+\Delta \mathrm{b}^{* 2}\right)^{1 / 2}$ [28].

\subsection{Proximate Analysis}

Moisture, protein, ash, and fat content were determined according to official methods [29]. Protein content was estimated by the Kjeldahl method, ash was determined by the dry ashing procedure, and fat content was determined using a Soxhlet apparatus, whereas total carbohydrates were calculated by difference.

\subsection{Fatty Acid Composition}

The fatty acid composition of the RB samples extracted with ether was determined using gas chromatography with flame ionization detection (Model Varian CP-3800, Middelburg, The Netherlands) based on the AOAC 996.06 method [30]. Fatty acid methyl esters were identified by comparison of their retention times with those of external standards ( $\mathrm{Su}-$ pelco 37 Component FAME Mix) and the amount of individual fatty acids was expressed as percentages $(\%)$ of the total fatty acids determined.

\subsection{Free Fatty Acids Content}

Free fatty acids contents of the lipid fraction of RB samples were determined using a standard titration method [31], and the results were calculated as oleic acid equivalent, which was expressed as a percentage of total lipids.

\subsection{Lipase Assay}

The lipase activity in RB samples was determined according to Rose and Pike [32] with some modification. Briefly, $1 \mathrm{~g}$ of defatted RB was weighed into each of two test tubes: one blank and one sample. Then, $400 \mu \mathrm{L}$ of olive oil and $200 \mu \mathrm{L}$ of distilled water were added to both tubes and mixed. The lipids from the blank were immediately extracted with $5 \mathrm{~mL}$ of hexane ( 2 times), the supernatants after centrifugation at $1000 \times g$ for $5 \mathrm{~min}$ were pooled and evaporated using a rotary vacuum evaporator, and the residue was redissolved in $4 \mathrm{~mL}$ of isooctane. The other test tube (sample) was incubated for $4 \mathrm{~h}$ at $40{ }^{\circ} \mathrm{C}$. After incubation, lipids were extracted as described for the blank, and both extracts were used for the lipase assay. An aliquot of $0.75 \mathrm{~mL}$ isooctane extract was mixed with $0.5 \mathrm{~mL}$ of $3 \%(v / v)$ pyridine in $5 \%(w / v)$ aqueous cupric acetate, the mixture was shaken for $1 \mathrm{~min}$, centrifuged for $1 \mathrm{~min}$, and the absorbance of supernatant was read at $715 \mathrm{~nm}$ and quantified against an external standard curve of oleic acid. The lipase activity was expressed as units per $\mathrm{g} R \mathrm{R}$ $(\mathrm{U} / \mathrm{g})$, where $1 \mathrm{U}$ was defined as the micromoles of fatty acid liberated per $\mathrm{h}$, according to Equation (1):

$$
\text { Lipase activity }=1000(4+v)(A s-A B) / \varepsilon t l s
$$

where $v=$ volume of olive oil added $(\mathrm{mL}), A s=$ absorbance of sample after incubation at $715 \mathrm{~nm}, A B=$ absorbance of blank at $715 \mathrm{~nm}, \varepsilon=$ molar absorptivity of oleic acid at $715 \mathrm{~nm}\left(\mathrm{M}^{-1} \cdot \mathrm{cm}^{-1}\right), t=$ incubation time $(\mathrm{h}), l=$ path length $(1 \mathrm{~cm}$ for a standard cuvette), and $s=$ sample weight $(\mathrm{g})$.

\subsection{Bioactive Components}

Free phenolic compounds were extracted twice from $0.25 \mathrm{~g}$ sample with $5 \mathrm{~mL}$ of $60 \%$ aqueous ethanol in an ultrasound bath at room temperature for $10 \mathrm{~min}$, followed by centrifugation at $10,000 \mathrm{rpm}$ for $10 \mathrm{~min}$ at $4{ }^{\circ} \mathrm{C}$. Bound phenolic compounds were recovered after the alkaline hydrolysis of the remained residue with $4 \mathrm{~N} \mathrm{NaOH}$ for 90 min under 
sonication, followed by acidification to $\mathrm{pH} 2.0$ with concentrated $\mathrm{HCl}$ and finally extraction with ethyl acetate. The ethyl acetate fraction was vacuum-evaporated at $40{ }^{\circ} \mathrm{C}$, and the residue was reconstituted in $4 \mathrm{~mL}$ of $70 \%$ aqueous methanol. Both free and bound fractions were stored at $-25^{\circ} \mathrm{C}$ until analysis.

Total phenolic content (TPC) of extracts was performed using the Folin-Ciocalteu's method according to Singleton et al. [33]. Briefly, extracts of $0.2 \mathrm{~mL}$ were mixed with $0.8 \mathrm{~mL}$ Folin-Ciocalteu reagent, $2 \mathrm{~mL}$ of sodium carbonate $(7.5 \% \mathrm{w} / \mathrm{v})$ solution, and distilled water until reaching a final volume of $10 \mathrm{~mL}$. The absorbance at $725 \mathrm{~nm}$ was recorded after incubation for $60 \mathrm{~min}$. The results were expressed as $\mathrm{mg}$ of gallic acid equivalents per $\mathrm{g}$ of sample on a dry basis (mg GAE/g dw).

Tocopherols and tocotrienols contents were determined as follows: $0.2 \mathrm{~g}$ of sample was sonicated twice with $2.5 \mathrm{~mL}$ ethanol for $10 \mathrm{~min}$, and the extract was collected after centrifugation at $1500 \times g$ for $10 \mathrm{~min}$. The combined supernatants were evaporated under the flow of nitrogen, the remaining residue was redissolved in $1 \mathrm{~mL}$ of a mixture acetonitrile/methanol $(85: 15, v / v)$, and finally, a $20 \mu \mathrm{L}$ aliquot was injected into an HPLC system (Agilent Technologies, 1200 series, Urdorf, Switzerland) equipped with a YMC $\mathrm{C}_{30}$ column $(250 \times 4.6 \mathrm{~mm}$ id, $3 \mu \mathrm{m}$, MZ Analysentechnik, Mainz, Germany); the chromatographic conditions were as described by Irakli et al. [34].

$\gamma$-oryzanol content was determined in the same extract as with tocol analysis. The separation was carried out using a Target $C_{18}(4.6 \times 150 \mathrm{~mm}, 5 \mu \mathrm{m}$, MZ Analysentechnik, Mainz, Germany) column at $30^{\circ} \mathrm{C}$, with mobile phase consisted of acetonitrile/methanol/ dichloromethane $(40: 45: 15, v / v / v)$ under isocratic conditions at a flow rate of $1.5 \mathrm{~mL} / \mathrm{min}$. $\gamma$-oryzanol was detected at $330 \mathrm{~nm}$. Quantitation was based on a linear calibration curve of the sum of the areas of four curves of $\gamma$-oryzanol standard, namely cycloartenyl ferulate, 24-methylene cycloartanyl ferulate, campesteryl ferulate and sitosteryl ferulate, as were analyzed by HPLC and confirmed by nuclear magnetic resonance (NMR) and MS by others researchers [35].

\subsection{Antinutritional Composition}

Oxalate content was determined using the titration method described by Oyeyinka et al. [36]. Firstly, $1 \mathrm{~g}$ of sample was extracted with $75 \mathrm{~mL}$ of $3 \mathrm{M}$ sulfuric acid under continuous mechanical stirring for $1 \mathrm{~h}$, followed by filtration. Then, $25 \mathrm{~mL}$ of the filtrate was heated at $70{ }^{\circ} \mathrm{C}$ and was titrated steadily against $0.05 \mathrm{M}$ potassium permanganate, until an extremely faint, pale pink end point color persistence was observed for $10 \mathrm{~s}$. Oxalate content was calculated by the equation: Oxalate $(\mathrm{mg} / \mathrm{g})=1.33 x$ titer value. The results were expressed on a dry basis.

Phytate content was evaluated using the method as described by Wheeler and Ferrel [37]. Firstly, $1 \mathrm{~g}$ of sample was macerated with $50 \mathrm{~mL}$ of $3 \%$ trichloroacetic acid (TCA) for $30 \mathrm{~min}$ with mechanical shaking. After centrifugation, a $10 \mathrm{~mL}$ aliquot of supernatant was mixed with $4 \mathrm{~mL}$ of $\mathrm{FeCl}_{3}$ (2 $\mathrm{mg}$ ferric ion per $\mathrm{mL}$ in TCA), and the mixture was boiled for $45 \mathrm{~min}$. After centrifugation, the precipitate was washed with $20-25 \mathrm{~mL} \mathrm{3 \%}$ TCA and was re-boiled for another $10 \mathrm{~min}$. The washing was repeated with water, and the precipitate was dispersed in few $\mathrm{mL}$ water and $3 \mathrm{~mL}$ of $1.5 \mathrm{~N} \mathrm{NaOH}$, and water was then added until the final volume of $30 \mathrm{~mL}$. The suspension was boiled for $30 \mathrm{~min}$, followed by filtration and washing with hot water, and the precipitate was dissolved with $40 \mathrm{~mL}$ of hot $3.2 \mathrm{~N} \mathrm{HNO}_{3}$ into a 100-mL volumetric flask that was filled with the washing water; then, a $5 \mathrm{~mL}$ aliquot of the above extract was transferred in a $100-\mathrm{mL}$ volumetric flask containing $70 \mathrm{~mL}$ water and $20 \mathrm{~mL} 1.5 \mathrm{~N} \mathrm{KSCN}$ was added, filled with water, and the absorbance was measured at $480 \mathrm{~nm}$ within $1 \mathrm{~min}$. Iron content from $\mathrm{Fe}\left(\mathrm{NO}_{3}\right)_{3}$ was measured via a standard curve, and phytate phosphorus was calculated from the iron results assuming a 4:6 iron/phosphorus molecular ratio with the results being expressed on dry basis.

Total saponin content was determined using a spectrophotometric method, as described by Hierro et al. [38]. Firstly, $0.5 \mathrm{~g}$ of sample was extracted with $10 \mathrm{~mL}$ of absolute ethanol in an ultrasonic bath for $20 \mathrm{~min}$ at $70{ }^{\circ} \mathrm{C}$. Then, the mixture was centrifuged at $4000 \mathrm{rpm}$ 
for $10 \mathrm{~min}$, and the above procedure was repeated. Combined supernatants were dried under vacuum, and the residue was reconstituted in $5 \mathrm{~mL}$ absolute ethanol. Aliquots of $250 \mu \mathrm{L}$ were mixed with $250 \mu \mathrm{L}$ of freshly prepared vanillin in ethanol $(0.8 \%, w / v)$ and $2.5 \mathrm{~mL}$ of sulfuric acid in water $(72 \%, v / v)$. Mixtures were vortexed, heated at $60{ }^{\circ} \mathrm{C}$ for $10 \mathrm{~min}$, cooled in ice for $5 \mathrm{~min}$, and the absorbance was recorded at $560 \mathrm{~nm}$ against the control sample containing ethanol. Results were expressed as $\mathrm{mg}$ diosgenin equivalent per g RB sample on dry basis.

Trypsin inhibitor activity was estimated by the method of Kakade et al. [39] as follows: $1 \mathrm{~g}$ of sample was extracted with $50 \mathrm{~mL}$ of $0.01 \mathrm{NaOH}$ with continuous shaking for $1 \mathrm{~h}$. The $\mathrm{pH}$ of the suspension was 9.5 to 9.8 , and the suspension was diluted to the point that $1 \mathrm{~mL}$ produces trypsin inhibition of 40 to $60 \%$. Then, portions of $0,0.6,1.0,1.4$, and $1.8 \mathrm{~mL}$ of the suspension were transferred into a double set of test tubes and adjusted to $2 \mathrm{~mL}$ with water. After the addition of $2 \mathrm{~mL}$ of trypsin $(0.2 \mathrm{mg} / \mathrm{mL})$, the tubes were boiled at $37{ }^{\circ} \mathrm{C}$ and $5 \mathrm{~mL}$ of BAPA solution $(40 \mathrm{mg}$ benzoyl $\cdot \mathrm{D} \mathrm{L} \cdot$ arginine-p-nitroanilide hydrochloride dissolved in $1 \mathrm{~mL}$ of dimethyl sulfoxide and diluted to $100 \mathrm{~mL}$ with Tris-buffer, $0.05 \mathrm{M}$, $\mathrm{pH} 8.2$, containing $0.02 \mathrm{M} \mathrm{CaCl}_{2}$ ) was added, and the mixture was incubated for exactly $10 \mathrm{~min}$. The reaction was terminated with $1 \mathrm{~mL} \mathrm{30 \%} \mathrm{acetic} \mathrm{acid,} \mathrm{and} \mathrm{the} \mathrm{absorbance} \mathrm{was}$ recorded at $410 \mathrm{~nm}$ against the reagent blank that was prepared by adding $1 \mathrm{~mL}$ of $30 \%$ acetic acid before the addition of BAPA. Trypsin inhibition activity is expressed in terms of trypsin units inhibited (TUI) taking into account that 1 TU is arbitrary defined as an increase of 0.01 absorbance units at $410 \mathrm{~nm}$ per $10 \mathrm{~mL}$ of extract on dry basis.

Tannins content was estimated as follows: Aliquots of about $400 \mu \mathrm{L}$ of the phenolic extract prepared as described above were treated with polyvinylpolypyrrolidone (40 $\mathrm{mg}$, $100 \mathrm{mg} / \mathrm{mL})$ at $4^{\circ} \mathrm{C}$ for $20 \mathrm{~min}$. After centrifugation at $10,000 \mathrm{rpm}\left(4^{\circ} \mathrm{C}, 10 \mathrm{~min}\right)$, non-tannin phenolics (supernatant) were determined as above by the Folin-Ciocalteu method [40]. Total tannins were calculated by subtracting non-tannin phenolics from total phenolics.

\subsection{Antioxidant Activity Assays}

Three assays were employed to determine the antioxidant activities of the RB extracts: 2,2'-azinobis-(3-ethylbenzothiazoline-6-sulphonate) radical (ABTS-+) scavenging activity (ABTS assay) [41], 1,1-diphenyl-2-picrylhydrazyl radical scavenging activity (DPPH assay) [42] and ferric-reducing antioxidant power (FRAP) [43]. Trolox was used as the standard compound for calibration curves and the results were expressed in $\mathrm{mg}$ of trolox equivalents (TE) per $\mathrm{g}$ of RB on dry basis (mg TE/g dw).

\subsection{Bulk Density}

Bulk density (BD) of RB samples was determined by the method described by Kaushala et al. [44]: $25 \mathrm{~g}$ of flour was gently filled into $50 \mathrm{~mL}$ graduated cylinders that were previously tared. The bottom of each cylinder was gently tapped several times, and the volume was measured. BD was calculated as the weight of the sample per unit volume of sample $(\mathrm{g} / \mathrm{mL})$.

\subsection{Functional Properties Determination}

The water absorption capacity (WAC) of the RB samples was determined according to Abebe et al. [45]: RB samples were dispersed in distilled water and diluted to $10 \mathrm{~g} / \mathrm{mL}$. The dispersions were held at room temperature for $30 \mathrm{~min}$ with continuous stirring and followed by centrifugation for $30 \mathrm{~min}$ at $4000 \times g$. Then, the supernatant was weighed, and the results were expressed as $g$ of water retained per $g$ of $\mathrm{RB}$.

Oil absorption capacity (OAC) was determined according to Kaushala et al. [44]: A RB sample $(0.5 \mathrm{~g})$ was mixed with $6 \mathrm{~mL}$ of corn oil in pre-weighed tubes and centrifuged for $25 \mathrm{~min}$ at $3000 \times \mathrm{g}$. After stirring for $1 \mathrm{~min}$ with a thin brass wire, the tubes were allowed for $30 \mathrm{~min}$ and then were centrifuged for $25 \mathrm{~min}$ at $3000 \times g$. The separated oil was removed with a pipette, and the tubes were inverted for $25 \mathrm{~min}$ to drain the oil prior to reweighing. The OAC was expressed as $g$ of oil bound per $g$ of the RB. 
The water absorption index (WAI) and water solubility index (WSI) were measured according to Abebe et al. [45]. First, $2.5 \mathrm{~g}$ of RB sample was mixed with $30 \mathrm{~mL}$ of distilled water, vortexed, and cooked for $10 \mathrm{~min}$ in a $90{ }^{\circ} \mathrm{C}$ water bath. After centrifugation at $4000 \times g$ for $10 \mathrm{~min}$, the supernatant was weighted and evaporated overnight at $110{ }^{\circ} \mathrm{C}$ to determine the soluble solids, and the sediment was weighed. The WAI was calculated by weighing the sediment and expressed as $g$ of absorbed water per $g$ of sample. WSI was calculated from the amount of soluble solids recovered from the supernatant divided by the sample weight $\times 100$. The swelling power (SP) was calculated by dividing the weight of sediment per the difference between the initial sample weight and the amount of dry solids of the supernatant $(\mathrm{g} / \mathrm{g})$.

The foaming capacity (FC) and foaming stability (FS) were determined using the method described by Kaushala et al. [44]. The dispersions of the sample $(1.5 \mathrm{~g}$ in $50 \mathrm{~mL}$ of distilled water) were homogenized, using an ultrasonic probe (Sonoplus, model HD 4100, Berlin, Germany) at high speed for 2-3 min. The suspension was immediately transferred into a graduated cylinder, and the homogenizer cup was rinsed with $10 \mathrm{~mL}$ of distilled water, which was then added to the graduated cylinder. The volume was recorded before and after whipping. FC was calculated by dividing the difference between the volume after and before the whipping per the volume before whipping $\times 100$. Foam volume changes in the graduated cylinder were recorded at an interval of $60 \mathrm{~min}$ of storage in order to estimate the FS.

Emulsifying activity (EA) was determined by the method of Nazck et al. [46]. First, $3.5 \mathrm{~g}$ sample of RB was homogenized for $30 \mathrm{~s}$ with $50 \mathrm{~mL}$ of water using an ultrasonic probe (Sonoplus model HD 4100, Berlin, Germany) at high speed. After the addition of $25 \mathrm{~mL}$ of corn oil, the mixture was again homogenized for $90 \mathrm{~s}$. The emulsion was centrifuged at $1100 \times g$ for $5 \mathrm{~min}$. The EA was calculated by dividing the volume of the emulsified layer by the volume of emulsion before centrifugation $\times 100$. The emulsion stability (ES) was determined by heating the above emulsion at $85^{\circ} \mathrm{C}$ for $15 \mathrm{~min}$, after which it was cooled and centrifuged. The ES was expressed as a percentage of the EA remaining after heating.

All results were expressed on dry basis to avoid the effect of different water content in the samples.

\subsection{Statistical Analysis}

Values were reported as the mean \pm standard deviation of triplicate measurements. All parameters were subjected to one-way analysis of variance (ANOVA), and when ANOVA revealed significant differences between means, a Tukey's test at $p<0.05$ was used to separate means by using the Minitab 17 (Minitab Inc., State College, PA, USA) software.

\section{Results and Discussion}

\subsection{Free Fatty Acids and Lipase Activity}

Heating treatments are the most widely used methods of RB stabilization. Stabilized RB offers multiple benefits including better quality characteristics and extended product shelf-life on storage, thus providing a wider range of RB fortified products for consumers. Novel technologies in food preservation have gained increased industrial interest as they are more environmentally and economically sustainable compared to conventional preservation methods. In this context, the effects of three different heating treatments, such as dry-heating, infrared-radiation, and microwave-heating, on the stabilization of RB were examined in the present study on a comparative basis. The applied conditions (temperature and time duration) for each heating treatment were selected according to preliminary results based on response surface methodology using relative lipase activity as a probe for the effectiveness of the treatment (data not shown). The free fatty acids (FFA) content and lipase activity of untreated and heat-treated RB samples were determined after 1 day of storage at room temperature. As shown in Figure 1, significant decreases $(p<0.05)$ on FFA content were observed in the heat-treated RB samples by all three methods of heat treatment employed. Among the heating treatments, dry-heating gave the lowest 
FFA content (3.91\%), whereas microwave-heating and infrared-radiation had similar FFA content with a mean value of $5.53 \%$.

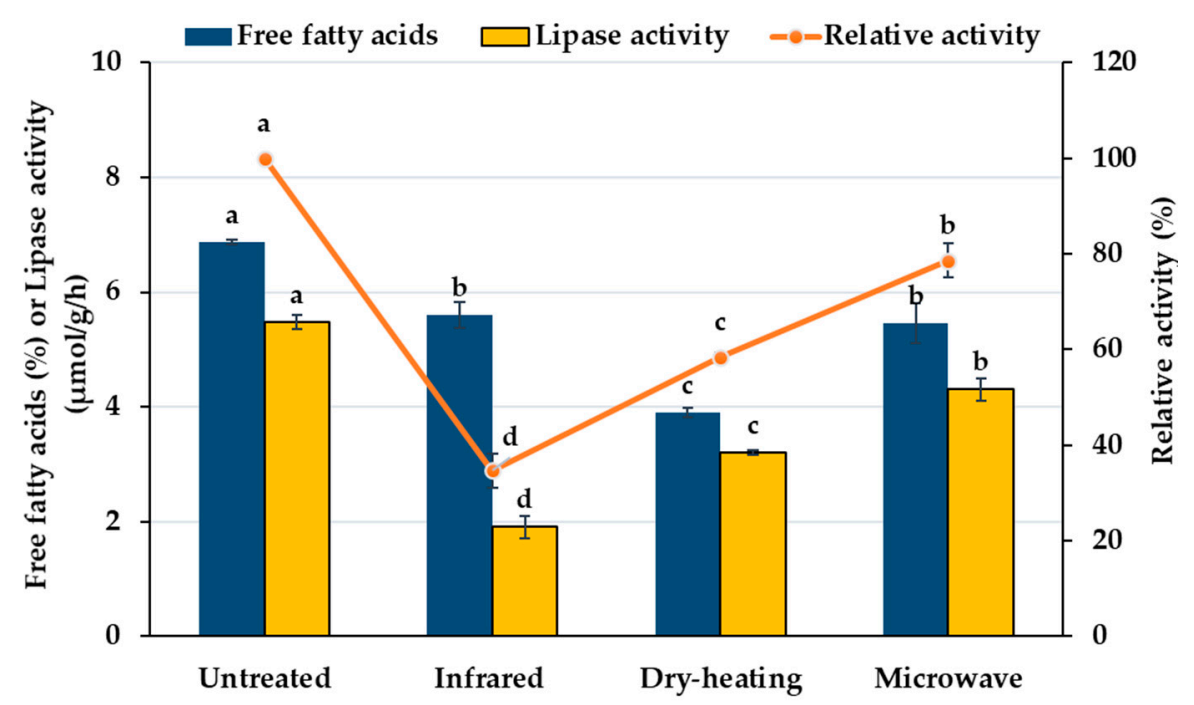

Figure 1. Effect of three different heating treatments (infrared-radiation, dry-heating, and microwaveheating) on free fatty acids content and relative lipase activity of RB samples; values followed by the same letter for the same estimated parameter are not significantly different $(p>0.05)$.

Lipase is the major cause of RB lipid deterioration i.e., hydrolytic oxidation. The changes in lipase activity as a result of stabilization treatments are also shown in Figure 1. Among the treatments, microwave-heating for $2 \mathrm{~min}$ at $650 \mathrm{Watt}$ resulted in the most inefficient stabilization (78.6\% relative enzymatic activity was remained). Dryheating at $140{ }^{\circ} \mathrm{C}$ for 40 min showed better stabilization results (lowest content of liberated FA), with remaining lipase activity at $\approx 58.5 \%$; moreover, infrared-radiation at the same temperature for $15 \mathrm{~min}$ gave even lower residual lipase activity of $34.8 \%$. Yu et al. [47] compared $11 \mathrm{RB}$ stabilization methods and found that among various heating treatments, autoclaving exerted the best inactivation effect, yielding $\approx 10.7 \%$ relative activity of lipase, whereas other heating methods resulted in about $30-35 \%$ residual lipase activities, except dry-heating (68.9\%). However, although autoclaving was the most effective method to inactivate the lipase of $\mathrm{RB}$, it is not easily applicable at an industrial scale. Furthermore, ultraviolet irradiation was found to be a promising alternative (convenient and energy-saving) stabilization method without influencing oil quality and nutrient content.

\subsection{Nutritional Profile}

The proximate analysis of untreated and heat-treated of RB samples, reflecting the major nutritional components, is presented in Table 1. As expected, the moisture content of all heat-treated RB samples is significantly lower $(p<0.05)$ than the untreated sample. Among the heat-treated samples, dry-heating significantly decreased the moisture content at the lowest level compared to microwave treatment, showing the highest level, whereas the infrared-radiation treatment gave an intermediate moisture content. The protein content was not affected significantly by the method of stabilization, ranging between 18.13 and $18.51 \%$. However, stabilization by all heating methods increased significantly $(p<0.05)$ the fat and ash contents, when the data were expressed on a dry basis. The increased fat in heat-treated RB may be attributed to structure loosening of the treated samples, permitting a more efficient fat extractability by the organic solvent [21]. As for the carbohydrate content of the RB samples, there seems to be a very slight reduction $(p<0.05)$ in all heat-treated materials. 
Table 1. Proximate composition (\% db) of rice bran (RB) samples before and after heat treatments.

\begin{tabular}{cccccc}
\hline Samples & Moisture & Protein & Fat & Ash & Carbohydrates \\
\hline Untreated & $10.93 \pm 0.07^{\mathrm{a}}$ & $18.39 \pm 0.03^{\mathrm{ab}}$ & $17.81 \pm 0.31^{\mathrm{b}}$ & $8.83 \pm 0.03^{\mathrm{b}}$ & $55.01 \pm 0.34^{\mathrm{a}}$ \\
Infrared & $5.48 \pm 0.05^{\mathrm{c}}$ & $18.13 \pm 0.10^{\mathrm{b}}$ & $18.76 \pm 0.37^{\mathrm{a}}$ & $8.94 \pm 0.04^{\mathrm{a}}$ & $54.42 \pm 0.27^{\mathrm{b}}$ \\
Dry-heating & $2.76 \pm 0.00^{\mathrm{d}}$ & $18.51 \pm 0.10^{\mathrm{a}}$ & $18.53 \pm 0.04^{\mathrm{a}}$ & $9.00 \pm 0.02^{\mathrm{a}}$ & $53.97 \pm 0.12^{\mathrm{b}}$ \\
Microwave $^{\mathrm{b}}$ & $8.30 \pm 0.01^{\mathrm{b}}$ & $18.37 \pm 0.10^{\mathrm{ab}}$ & $18.74 \pm 0.18^{\mathrm{a}}$ & $8.96 \pm 0.01^{\mathrm{a}}$ & $53.94 \pm 0.02^{\mathrm{b}}$ \\
\hline
\end{tabular}

Values are means \pm standard deviation $(n=3)$, while different letters for values in each column indicate significant differences $(p<0.05)$; db: dry basis.

\subsection{Fatty Acid Profile}

The fatty acid composition of untreated and heat-stabilized RB oils (Table 2) has been determined to assess the effect of stabilization treatment. In general, RB oil is rich in polyunsaturated $(41.70-42.60 \%)$, followed by monounsaturated $(37.14-37.68 \%)$ and saturated fatty acids $(19.50-20.03 \%)$. Palmitic $(16.30-16.60 \%)$, oleic $(36.30-36.80 \%)$, and linoleic acids (40.05-40.91\%) were found to be the three dominant fatty acids, as previously reported in the literature [13-15]. The rations of polyunsaturated/saturated FAs (PUFA/SFA) and $\omega 6 / \omega 3$ for untreated RB were 2.12 and 24.64, respectively, while the heat-treated RB samples were in the range of 2.08-2.19 and 24.35-26.66, respectively, without any significant change for the heated RB samples compared to the untreated RB. According to the nutritionally recommended values for the PUFA/SFA ratio (higher than 0.45 ) and $\omega 6 / \omega 3$ ratio (a range between 4:1 and 10:1, due to differing opinions in the literature) [48], it can be concluded that the PUFA/SFA ratio of RB is beneficial to health, whereas the $\omega 6 / \omega 3$ ratio does not comply with a desired good nutritional index [49].

Table 2. Fatty acid profile of RB samples before and after heat treatments (\% of the total fatty acids).

\begin{tabular}{|c|c|c|c|c|}
\hline Fatty Acids & Untreated & Infrared & Dry-Heating & Microwave \\
\hline Myristic acid (C14:0) & $0.36 \pm 0.01^{\mathrm{c}}$ & $0.41 \pm 0.01^{\mathrm{a}}$ & $0.38 \pm 0.01^{b}$ & $0.35 \pm 0.01 \mathrm{bc}$ \\
\hline Palmitic acid (C16:0) & $16.30 \pm 0.30^{\mathrm{a}}$ & $16.30 \pm 0.50^{\mathrm{a}}$ & $16.55 \pm 0.15^{\mathrm{a}}$ & $16.60 \pm 0.10^{\mathrm{a}}$ \\
\hline Stearic acid (C18:0) & $1.30 \pm 0.01^{\mathrm{a}}$ & $1.19 \pm 0.03^{b}$ & $1.31 \pm 0.01^{\mathrm{a}}$ & $1.30 \pm 0.01^{\mathrm{a}}$ \\
\hline Oleic acid (C18:1, cis-9) & $36.75 \pm 0.15^{\mathrm{a}}$ & $36.30 \pm 0.70^{\mathrm{a}}$ & $36.70 \pm 0.10^{\mathrm{a}}$ & $36.80 \pm 0.10^{\mathrm{a}}$ \\
\hline Linoleic acid (C18:2 cis-9,12), n6 & $40.29 \pm 0.22^{a}$ & $40.91 \pm 1.06^{\mathrm{a}}$ & $40.05 \pm 0.25^{\mathrm{a}}$ & $40.25 \pm 0.15^{a}$ \\
\hline $\begin{array}{c}\alpha \text {-Linolenic acid (C18:3, } \\
\text { cis-9,12,15), n3 }\end{array}$ & $1.64 \pm 0.02^{\mathrm{a}}$ & $1.54 \pm 0.12^{\mathrm{a}}$ & $1.64 \pm 0.01^{\mathrm{a}}$ & $1.65 \pm 0.02^{a}$ \\
\hline Arachidic acid (C20:0) & $0.64 \pm 0.01^{\mathrm{a}}$ & $0.51 \pm 0.01^{\mathrm{c}}$ & $0.58 \pm 0.01^{b}$ & $0.57 \pm 0.01^{b}$ \\
\hline cis-11-Eicosenoic acid (C20:1) & $0.55 \pm 0.01^{\mathrm{ab}}$ & $0.52 \pm 0.01^{\mathrm{c}}$ & $0.55 \pm 0.01^{\mathrm{a}}$ & $0.53 \pm 0.01^{b c}$ \\
\hline Behenic acid (C22:0) & $0.27 \pm 0.01^{b}$ & $0.28 \pm 0.01^{\mathrm{b}}$ & $0.28 \pm 0.01^{\mathrm{a}}$ & $0.29 \pm 0.01^{\mathrm{a}}$ \\
\hline Lignoceric acid (C24:0) & $0.76 \pm 0.01^{b}$ & $0.71 \pm 0.02^{\mathrm{c}}$ & $0.82 \pm 0.02^{\mathrm{a}}$ & $0.75 \pm 0.01^{\mathrm{b}}$ \\
\hline Saturated fatty acids (SFA) & $19.74 \pm 0.28^{\mathrm{a}}$ & $19.50 \pm 0.55^{\mathrm{a}}$ & $20.03 \pm 0.18^{a}$ & $20.02 \pm 0.09^{a}$ \\
\hline Monounsaturated fatty acids & $37.64 \pm 0.14^{\mathrm{a}}$ & $37.14 \pm 0.70^{\mathrm{a}}$ & $37.63 \pm 0.08^{a}$ & $37.68 \pm 0.10^{a}$ \\
\hline $\begin{array}{c}\text { Polyunsaturated fatty acids } \\
\text { (PUFA) }\end{array}$ & $41.93 \pm 0.20^{a}$ & $42.60 \pm 0.98^{a}$ & $41.70 \pm 0.25^{\mathrm{a}}$ & $41.92 \pm 0.17^{\mathrm{a}}$ \\
\hline PUFA/SFA & $2.12 \pm 0.04^{\mathrm{a}}$ & $2.19 \pm 0.11^{\mathrm{a}}$ & $2.08 \pm 0.03^{\mathrm{a}}$ & $2.09 \pm 0.02^{\mathrm{a}}$ \\
\hline$\omega 6$ & $40.36 \pm 0.16^{\mathrm{a}}$ & $40.92 \pm 1.04^{\mathrm{a}}$ & $40.21 \pm 0.17^{\mathrm{a}}$ & $40.30 \pm 0.13^{\mathrm{a}}$ \\
\hline$\omega 3$ & $1.64 \pm 0.02^{\mathrm{a}}$ & $1.54 \pm 0.12^{\mathrm{a}}$ & $1.64 \pm 0.01^{\mathrm{a}}$ & $1.65 \pm 0.02^{\mathrm{a}}$ \\
\hline$\omega 6 / \omega 3$ & $24.64 \pm 0.40^{\mathrm{a}}$ & $26.66 \pm 2.66^{\mathrm{a}}$ & $24.59 \pm 0.07^{\mathrm{a}}$ & $24.35 \pm 0.15^{\mathrm{a}}$ \\
\hline
\end{tabular}

Minor fatty acids were lauric (C12:0), pentadecanoic (C15:0), heptadecanoic (C17:0), cis-10 heptadecenoic (C17:1), linolelaidic (C18:2, trans-9,12), erucic (C22:1, cis-13), tricosanoic (C23:0). Means with same superscript letter within the same line are not significantly different $(p>0.05)$.

The effect of heat treatments on the fatty acid composition of RB was found to be statistically insignificant $(p>0.05)$, as already observed by Yilmaz et al. [14] and Irakli et al. [15]. However, for infrared-radiation treatment, a slight increase in polyunsaturated and a decrease in monounsaturated and saturated fatty acids were noted compared to the untreated sample. Similarly, Ramezanzadeh et al. [13] found no significant differences for the fatty acids between stabilized RB by microwave-heating and the raw RB. 


\subsection{Color Parameters}

Color is an important quality determinant, influencing consumer preference for certain food products. The effects of different heating treatments on the color changes of RB are shown in Figure 2. The color values $\left(\mathrm{L}^{*}\right.$ and $\left.\mathrm{b}^{*}\right)$ were affected significantly $(p<0.05)$ by all three heating methods; however, no differences were noted among the heating treatments $(p>0.05)$. The RB stabilized with microwave-heating exhibited the brightest brown color, as evidenced from the highest $\Delta \mathrm{E}^{*}$ values among all stabilized RB samples. The color parameters of the stabilized RB samples were comparable to those of RB stabilized by other methods in previous studies; Rodchuajeen et al. [50] reported color values in the range of 62-64 for $\mathrm{L}^{*}, 5.5-5.9$ for $\mathrm{a}^{*}, 18.2-19.1 \mathrm{for}^{*}$, and 6.1-8.2 for $\Delta \mathrm{E}^{*}$ for stabilized RB samples by different moving-bed drying methods.

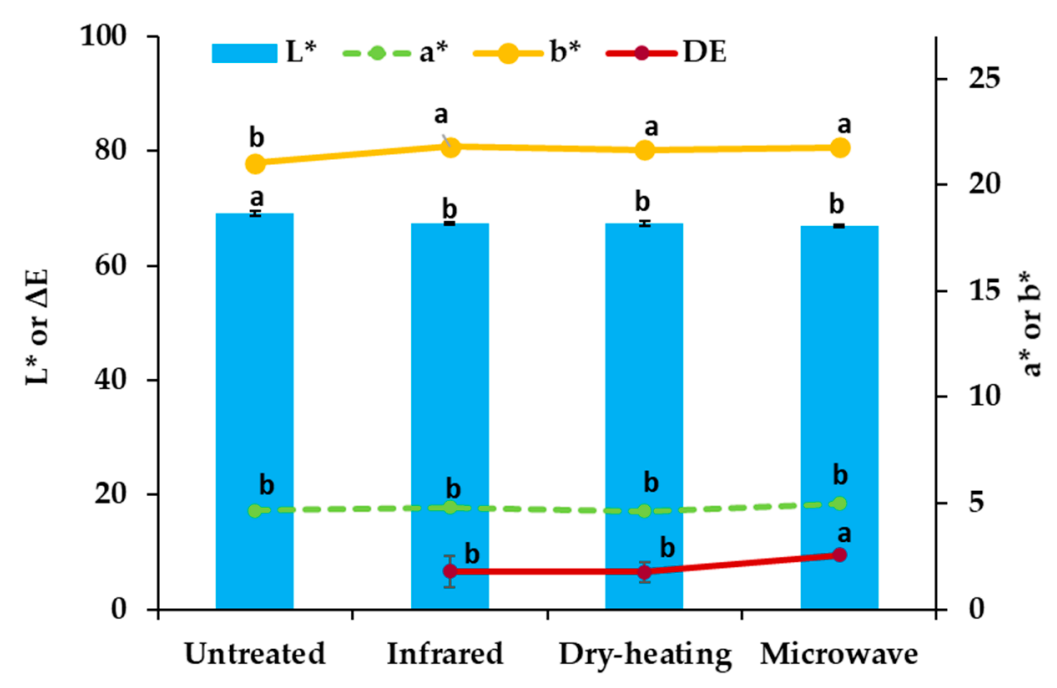

Figure 2. Effect of three different heating treatments (infrared-radiation, dry-heating, and microwaveheating) on color values of RB samples; values on bars or lines with specified by different letter are significantly different from each other $(p<0.05)$.

\subsection{Antinutritional Components}

Although the increased consumption of cereal bran in the diet is encouraged by nutritionists to increase overall fiber intake, no consideration of the antinutritional components has ever been, although antinutrients are known to impair food digestion and absorption. The antinutritional composition of the RB samples before and after heat treatments is presented in Table 3. Stabilization treatments significantly reduced the antinutritional components. Overall, the highest phytate, oxalate, saponins, and trypsin inhibition levels were found in untreated $\mathrm{RB}$, whereas heating treatments reduced all these antinutritional components. Phytate has been considered as an antinutrient because of its ability to interact with minerals, proteins, and starch, resulting in insoluble complexes that modify the functionality, digestion, and absorption of these food components [51]. The phytate content of untreated and treated RB samples ranged between 20.04 and $27.08 \mathrm{mg} / \mathrm{g}$ dw. Similar values are reported by Kaur et al. [52], although a large variation in phytate content is often found in the literature due to genotypic and environmental effects or different extraction rates adopted upon milling of rice grains. In the present study, the greatest reduction in phytate content was noted for the microwave stabilized $\mathrm{RB}(\approx 26.0 \%)$ followed by the infrared-radiation treated $(\approx 22.2 \%)$ and the dry-heating treated $\mathrm{RB}(\approx 19.9 \%)$; however, no differences were observed among the heated-treated RB samples $(p>0.05)$. Previous work by Sharma et al. [21] showed a significant reduction in phytate content during the extrusion processing of RB. Similarly, Khan et al. [26] reported that several stabilization treatments significantly reduce the phytate content of RB. The phytic acid reduction by heating treatments may be partially due to the heat labile nature of phytic acid and the formation of insoluble complexes between phytate and other components [53]. 
Table 3. Antinutritional composition of RB samples before and after heat treatments.

\begin{tabular}{cccccc}
\hline Samples & $\begin{array}{c}\text { Phytate } \\
(\mathbf{m g} / \mathbf{g ~ d w})\end{array}$ & $\begin{array}{c}\text { Oxalate } \\
(\mathbf{m g} / \mathbf{g} \text { dw) }\end{array}$ & $\begin{array}{c}\text { Saponins } \\
(\mathbf{m g} / \mathbf{g} \text { dw) }\end{array}$ & $\begin{array}{c}\text { Tannins } \\
(\mathbf{m g} / \mathbf{g} \mathbf{d w})\end{array}$ & $\begin{array}{c}\text { Trypsin } \\
\text { Inhibition } \\
\text { (TUI/g dw) }\end{array}$ \\
\hline Untreated & $27.08 \pm 0.73^{\mathrm{a}}$ & $6.52 \pm 0.15^{\mathrm{a}}$ & $89.70 \pm 0.28^{\mathrm{a}}$ & $3.39 \pm 0.16^{\mathrm{a}}$ & $14.93 \pm 0.79^{\mathrm{a}}$ \\
Infrared & $21.06 \pm 0.46^{\mathrm{b}}$ & $4.96 \pm 0.07^{\mathrm{c}}$ & $78.98 \pm 1.59^{\mathrm{b}}$ & $3.27 \pm 0.02^{\mathrm{a}}$ & $10.84 \pm 0.37^{\mathrm{b}}$ \\
Dry-heating & $21.70 \pm 0.11^{\mathrm{b}}$ & $5.80 \pm 0.04^{\mathrm{b}}$ & $62.35 \pm 2.57^{\mathrm{c}}$ & $3.37 \pm 0.06^{\mathrm{a}}$ & $10.08 \pm 0.10^{\mathrm{b}}$ \\
Microwave & $20.04 \pm 1.00^{\mathrm{b}}$ & $4.25 \pm 0.07^{\mathrm{d}}$ & $65.87 \pm 0.82^{\mathrm{c}}$ & $3.44 \pm 0.14^{\mathrm{a}}$ & $10.31 \pm 0.38^{\mathrm{b}}$ \\
\hline
\end{tabular}

Values are mean \pm standard deviation, while same letter along a column indicates no significant differences at $p>0.05 ; \mathrm{dw}$, dry-weighted.

Oxalate is also considered as an antinutritional component, as it can form nonabsorbable salts with sodium, calcium, and ammonium ions, rendering these minerals unavailable [54]. High intakes of soluble oxalate may cause calcium oxalate crystallization and the formation of kidney stones (nephrolithiasis) in the urinary tract [55]. The effect of heating treatments on the oxalate content of RB is indicated in Table 3. Significant variation was noted in oxalate content among the RB samples. The oxalate content of untreated RB was $6.52 \mathrm{mg} / \mathrm{g} \mathrm{dw}$, which was reduced to $4.96,4.25$, and $5.80 \mathrm{mg} / \mathrm{g} \mathrm{dw}$ with the infrared-radiation, microwave-heating, and dry-heating, respectively. Among the different heating treatments, microwave-heating was found most effective in reducing the oxalate content in RB by 34.9\%. Kaur et al. [52] also reported a lower level of oxalate content subjected to extrusion cooking, compared to its untreated counterpart.

Trypsin inhibitors, being low molecular weight proteins, were significantly inactivated $(p<0.05)$ by all heating treatments employed, as illustrated in Table 3 . The trypsin inhibition was minimum in the dry-heated RB, followed by microwave-heated and infrared-radiationtreated RB samples; i.e., dry-heating, microwave-heating, and infrared-radiation was effective in reducing the trypsin inhibitor activity by $\approx 32.5,31.0$, and $27.4 \%$, respectively. It has been reported that heat treatments such as microwave treatment, cooking, and autoclaving inactivate the trypsin inhibitors as a result of denaturation of these heat-labile proteins [56]. It has been suggested that reactions involving deamidation (splitting of covalent bonds) and the destruction of disulfide bonds might be responsible for the thermal inactivation process [52].

Saponins have the ability to bind proteins, enhancing protein stability against heat denaturation and decreasing the susceptibility of proteins to proteases. They may also cause gastrointestinal lesions, entering into the blood stream and hemolyzing the red blood cells [57]. The data displayed in Table 3 show the effect of stabilization on the saponin content of RB. All heating treatments resulted in a significant reduction of the saponin content, with the dry and microwave-heating presenting the maximum percentage reduction in saponin content at $\approx 30.5$ and $26.6 \%$, respectively, whereas the infrared radiation was less effective (reduction $\sim 12.0 \%$ ). The loss of saponins during microwave heating might be attributed to the thermo-labile nature of these compounds.

Although tannins form tannin-protein complexes leading to the inactivation of digestive enzymes and protein insolubility, they are considered effective in lowering blood glucose levels by delaying intestinal glucose absorption, thus delaying the onset of insulindependent diabetes mellitus [58]. In the present study, dry-heating, microwave processing, and infrared-radiation did not seem to reduce the total tannin content, in contrast to all other antinutritional components studied. Similarly, Sahni and Sharma et al. [59] also found that thermal processing treatments on alfalfa seeds showed less reduction in tannin content than other treatments. Moreover, Osman [60] found that the tannins content increased in roasted or cooked lablab beans due to the inhibition of polyphenol oxidase after heat treatment. However, Deng et al. [61] reported a significant reduction of tannins in buckwheat grains after cooking and microwave treatment. 


\subsection{Bioactive Components}

The principal bioactive compounds that contribute to the promising health-related benefits of RB comprise of phenolic compounds, tocols, and sterol derivatives (particularly $\gamma$-oryzanol). The phenolic compounds in RB exhibit antioxidant activity and may reduce free radical-mediated cellular damage. The TPC of each of the stabilized RB samples was determined using the Folin-Ciocalteu method in both free and bound forms. Our results demonstrate that total TPC decreased $(p<0.05)$ as a result of the thermal stabilization of RB (Table 4$)$, with significant differences $(p<0.05)$ among heat treatment applied. Untreated RB had the highest total TPC, followed by microwave-heated, infrared-radiated, and dry-heated RB samples. The free and bound TPC decreased by $16.5 \%$ and $10.3 \%$ after dry-heating, by $12.3 \%$ and $11.1 \%$ after infrared-radiation, and by $11.4 \%$ and $8.1 \%$ after microwave-heating treatment, respectively. Similar observations have been made by Rodchuajeen et al. [50], showing that heat processing can reduce the polyphenolic components of RB. In contrast, Saji et al. [62] found that stabilized RB by dry-heating had higher TPC than the untreated material. This discrepancy may be due to the fact that different factors, such as extraction parameters, varietal differences, bran fraction, and environmental conditions during the growing season may have a compositional impact and modulate the effects of the stabilization treatments.

Table 4. Bioactive components of RB samples before and after heat treatments.

\begin{tabular}{|c|c|c|c|c|c|}
\hline Samples & Fractions & Untreated & Infrared & Dry-Heating & Microwave \\
\hline \multirow{3}{*}{$\begin{array}{c}\mathrm{TPC}(\mathrm{mg} \\
\mathrm{GAE} / \mathrm{g} \mathrm{dw})\end{array}$} & Free & $5.99 \pm 0.05^{\mathrm{a}}$ & $5.15 \pm 0.06^{c}$ & $5.00 \pm 0.01^{d}$ & $5.31 \pm 0.01^{b}$ \\
\hline & Bound & $1.80 \pm 0.02^{\mathrm{a}}$ & $1.60 \pm 0.06^{b}$ & $1.62 \pm 0.03^{b}$ & $1.65 \pm 0.04^{b}$ \\
\hline & Total & $7.79 \pm 0.03^{\mathrm{a}}$ & $6.75 \pm 0.01^{c}$ & $6.61 \pm 0.02^{\mathrm{d}}$ & $6.96 \pm 0.02^{b}$ \\
\hline \multirow{3}{*}{$\begin{array}{l}\text { Tocols (mg } \\
100 / g \text { dw) }\end{array}$} & $\mathrm{T} 3 \mathrm{~s}$ & $13.45 \pm 0.20^{\mathrm{a}}$ & $11.42 \pm 0.31^{b}$ & $10.96 \pm 0.23^{b}$ & $11.59 \pm 0.41^{b}$ \\
\hline & Ts & $3.22 \pm 0.03^{\mathrm{a}}$ & $2.54 \pm 0.01^{\mathrm{b}}$ & $2.58 \pm 0.01^{b}$ & $2.57 \pm 0.26^{b}$ \\
\hline & Total & $16.67 \pm 0.16^{\mathrm{a}}$ & $13.96 \pm 0.31^{b}$ & $13.54 \pm 0.24^{b}$ & $14.16 \pm 0.67^{b}$ \\
\hline \multicolumn{2}{|c|}{$\gamma$-Oryzanol $(\mathrm{mg} / \mathrm{g} \mathrm{dw})$} & $2.44 \pm 0.04^{\mathrm{a}}$ & $2.37 \pm 0.03^{\mathrm{ab}}$ & $2.40 \pm 0.01^{\mathrm{ab}}$ & $2.32 \pm 0.13^{\mathrm{ab}}$ \\
\hline \multirow{3}{*}{$\begin{array}{c}\text { DPPH (mg } \\
\text { TE/g dw) }\end{array}$} & Free & $7.75 \pm 0.06^{\mathrm{a}}$ & $6.79 \pm 0.14^{b}$ & $6.69 \pm 0.05^{b}$ & $6.85 \pm 0.09^{b}$ \\
\hline & Bound & $2.72 \pm 0.19^{\mathrm{a}}$ & $2.17 \pm 0.02^{b}$ & $2.39 \pm 0.15^{b}$ & $2.79 \pm 0.08^{a}$ \\
\hline & Total & $10.46 \pm 0.25^{\mathrm{a}}$ & $8.96 \pm 0.12^{c}$ & $9.08 \pm 0.20^{c}$ & $9.64 \pm 0.01^{b}$ \\
\hline \multirow{3}{*}{$\begin{array}{l}\text { ABTS (mg } \\
\text { TE/g dw) }\end{array}$} & Free & $14.73 \pm 0.11^{\mathrm{a}}$ & $12.92 \pm 0.18^{c}$ & $12.69 \pm 0.30^{c}$ & $13.61 \pm 0.11^{b}$ \\
\hline & Bound & $5.35 \pm 0.33^{c}$ & $5.05 \pm 0.49^{c}$ & $12.65 \pm 0.41^{b}$ & $13.03 \pm 0.29^{a}$ \\
\hline & Total & $20.73 \pm 0.48^{c}$ & $18.27 \pm 0.34^{\mathrm{d}}$ & $25.70 \pm 0.72^{b}$ & $27.82 \pm 0.43^{a}$ \\
\hline \multirow{3}{*}{$\begin{array}{l}\text { FRAP (mg } \\
\text { TE/g dw) }\end{array}$} & Free & $6.61 \pm 0.04^{b}$ & $7.13 \pm 0.17^{\mathrm{a}}$ & $6.58 \pm 0.06^{b}$ & $5.01 \pm 0.01^{c}$ \\
\hline & Bound & $2.46 \pm 0.08^{c}$ & $2.55 \pm 0.03^{c}$ & $3.69 \pm 0.03^{b}$ & $3.98 \pm 0.16^{\mathrm{a}}$ \\
\hline & Total & $9.08 \pm 0.12^{\mathrm{c}}$ & $9.68 \pm 0.20^{b}$ & $10.27 \pm 0.10^{\mathrm{a}}$ & $8.99 \pm 0.14^{\mathrm{c}}$ \\
\hline
\end{tabular}

Values are mean \pm standard deviation, while same letter along a line indicates no significant differences $(p>0.05)$. TPC: total phenolic content.

The major lipophilic fractions of RB are tocopherols, tocotrienols (known as tocols), and $\gamma$-oryzanol that are characterized as the strongest antioxidants in RB [9]. According to the results presented in Table 4, the contents of tocotrienols and tocopherols in heat-treated RB were significantly lower than the untreated material $(p<0.05)$, which was presumably due to the degradation of the heat-sensitive antioxidants, with a loss of 15.8 and $20.5 \%$ for tocopherols and tocotrienols, respectively. On the contrary, $\gamma$-oryzanol was not reduced significantly $(p<0.05)$ by all heat treatments, as it has been reported to be a relatively thermostable antioxidant [63]. Untreated RB had the highest $\gamma$-oryzanol content, whereas the microwave-heated RB the lowest concentration among all the heat-treated RB samples. Similar results have been reported in the study of Lakkakula et al. [64] in which ohmic heat processing was adopted for RB stabilization. 
The effects of heat treatments on the antioxidant activity of RB were evaluated by three different methods, and the results are given in Table 4. Generally, greater antioxidant activity was observed in the free phenolic extract, as evaluated by the three tests (DPPH, ABTS, and FRAP). The DPPH free radical method is being used extensively to evaluate reducing substances. It has been noted that the DPPH radical scavenging activity of free RB phenolics was on average 2.6 times higher than those of the extracts of bound phenolics. A significant decrease in DPPH radical scavenging activity of the free phenolic fractions as well as total phenolics appeared upon heat treatment; nevertheless, the DPPH values of the bound fractions were not altered significantly, except in the case of the infrared-radiation and the dry-heating treatments. Such reductions go in parallel with the reduction in TPC and could be attributed to the formation of an irreversible covalent bond between liberated phenolic compounds and proteins [65].

A similar trend was observed for ABTS radical scavenging activity in the case of extracts of free phenolics, as the ABTS scavenging capacity decreased for all heat-stabilized RB samples (Table 4). However, for the bound phenolic extracts, the ABTS scavenging capacity increased after heat-stabilization, particularly for samples subjected to dry and microwave heat treatments $(\approx 2.4$ folds). This could be due to the differences in the type of radicals and phenolic compounds in both extracts. The presence of other phenolic compounds and non-phenolic antioxidants in the free extracts could also contribute to the antioxidant potential of these materials. Despite the large differences observed between free and bound phenolic extracts, which is in contrast to the DPPH assay, higher antioxidant activity was also noted in a study by Saji et al. [62] in which microwave and dry-heating methods were adopted for the RB stabilization. Overall, among all stabilization treatments, dry-heating and microwave-heating led to 23.9 and $34.2 \%$ increase in total ABTS value, respectively, while the infrared-radiation did not bring a significant change.

For the bound phenolic extracts, the antioxidant capacity of all stabilized RB samples, using the FRAP test, was increased compared to the untreated RB, and this was more pronounced to microwave-treated RB sample (Table 4). Some differences in the antioxidant activity values were also noted among the free phenolic extracts; the sample treated with infrared radiation exhibited the highest value for antioxidant capacity. The enhanced antioxidant activity of heat-treated RB samples may be due to the generation and accumulation of Maillard-derived melanoidins at high temperatures [66].

\subsection{Functional Properties}

The bulk density (BD) is a key factor for the storage, transportation, and processing of dry powders in food product formulations. In our study, the BD of RB samples varied from 0.33 to $0.36 \mathrm{~g} / \mathrm{mL}$. The stabilization by all heat treatments slightly decreased the BD of RB. The lower values for $\mathrm{BD}(p<0.05)$ were observed for the infrared-treated and dry-heated RB (Figure 3a), which was presumably due to some structural collapse of the material, leading to decreased porosity. A slightly higher BD in the microwave-heated RB reflects a more compact structure for these materials.

The functional properties of RB are important for its technological interest and physiological effects. The hydration properties of the RB dietary fiber determine their optimal usage levels in composite food matrices, since a desirable texture should be always retained [67]. The water absorption capacity (WAC) of RB samples ranged from 3.42 to $4.29 \mathrm{~g} / \mathrm{g} \mathrm{dw}$ (Figure 3a), which is within the range of 1.49-4.72 g/g, which is considered critical in viscous food dispersions [68]. The results indicate that the WAC of RB was affected significantly $(p<0.05)$ by the application of different methods of stabilization. Specifically, the WAC of stabilized RB by dry-heating and microwave-heating improved by 8.4 and $14.8 \%(p<0.05)$, respectively, making it a more suitable ingredient in foods where a greater water absorption is targeted (e.g., baked goods). However, the infrared-radiation treatment decreased significantly the WAC of RB compared to the untreated sample. In general, the relatively high WAC of the RB materials might be due to the presence of the hydroxyl group bearing polysaccharide components and the polar amino acids at the bran 
particle-water interface [27]. Similarly, Rafe et al. [68] found that the stabilization of RB by extrusion improved up to $20 \%$ the WAC; however, Khan et al. [27] indicated that the WAC of RB stabilized by dry-heating and microwave-heating was not significant $(p>0.05)$ as a result of the applied thermal treatment.
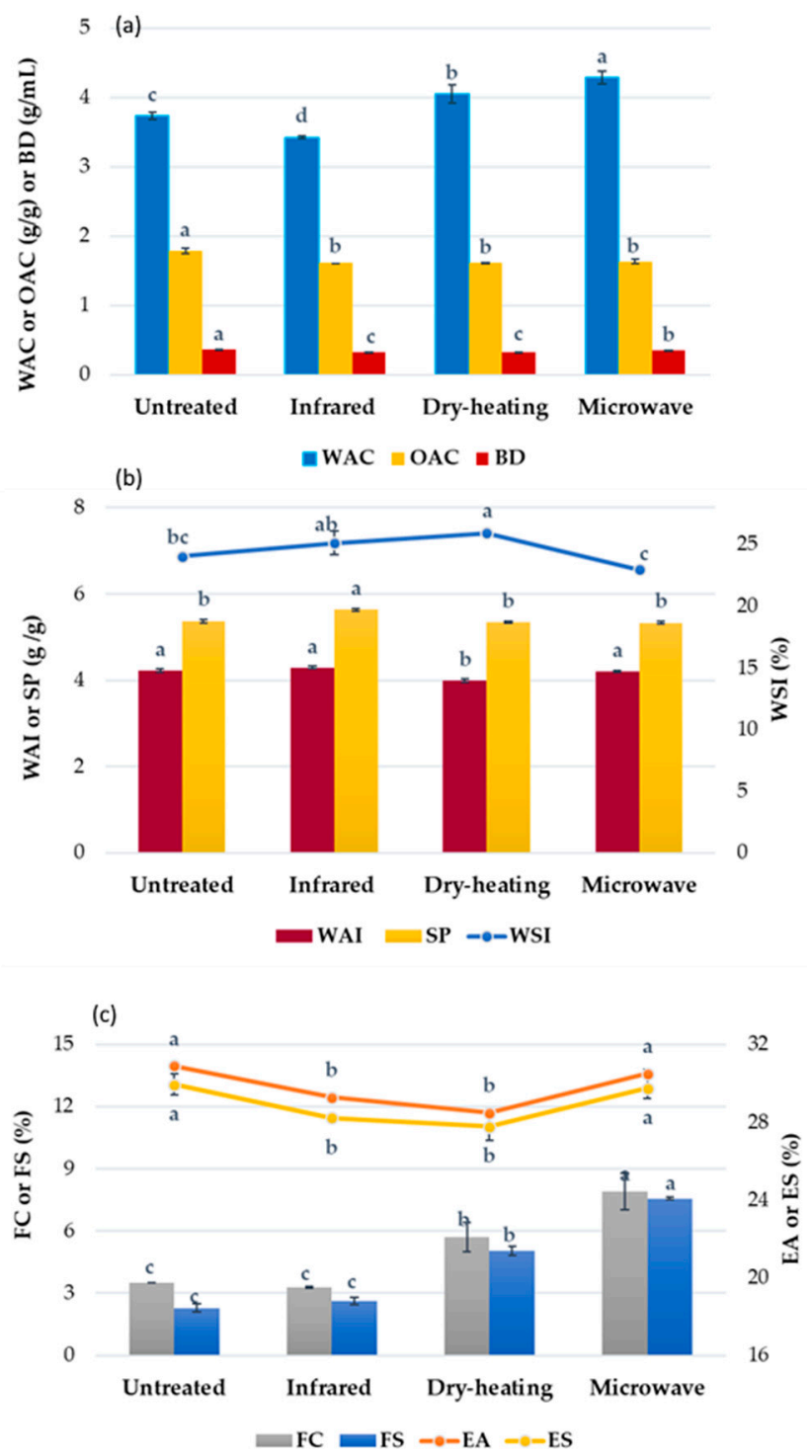

Figure 3. Effect of three different heating treatments (infrared-radiation, dry-heating, and microwaveheating) on WAC, OAC and BD (a), WAI, WSI and SP (b) and FC, FS, EA and ES (c) of RB samples; values followed by the same letter for the same physicochemical parameter are not significantly different $(p>0.05)$. WAC: Water Absorption Capacity, OAC: Oil Absorption Capacity, BD: Bulk Density, WAI: Water Absorption Index, SP: Swelling Power, WSI: Water Solubility Index, FC: Foaming Capacity, FS: Foaming Stability, EA: Emulsifying Activity, ES: Emulsion Stability.

Oil absorption capacity (OAC) is another important functional property, which is related to mouthfeel perception of the final product. A high OAC is essential in food systems such as processed meats (sausages), cake batters, mayonnaise, and salad dressings. According to the results of Figure $3 a$, the heat-treated RB samples showed slightly less strength for binding oil as compared to their counterpart. This might imply decreased surface hydrophobicity following the heat treatment. A lower hydrophobicity of the stabilized RB particles would not enhance the interactions between the fiber matrix of the $\mathrm{RB}$ and the oil, resulting in decreased oil absorption capacity [69]. 
The water absorption index (WAI) is the amount of water absorbed by starch or other particulate materials after swelling in an excess of water. In the case of starch, it can be related to starch gelatinization, which is greatly affected by the temperature and moisture content of the heated raw material [70]. The WAI was not affected significantly $(p>0.05)$ with the infrared-radiation and microwave-heating of RB stabilization (Figure $3 \mathrm{~b}$ ). Among all heat treatments applied, the dry-heating brought about the highest influence on WAI, leading to a $5.4 \%$ decrease in WAI of stabilized RB. The water solubility index (WSI) measures the amount of solubles (mostly low molecular weight material and watersoluble polysaccharides) released from a starch-containing material after thermal treatment. It is generally used as an indicator of material phase change (e.g., starch gelatinization) and/or some degradation of molecular components present in the heated particles [69]. The increase of WSI with heat treatment was more pronounced in the dry-heated RB, which was followed by the infrared-radiated RB, whereas the microwave-heated RB showed similar WSI with the untreated sample, as shown in Figure $3 \mathrm{~b}$. This may be due to the higher moisture content of RB treated by microwaves compared to the other samples [70]. Similar results were also reported for RB stabilized by extrusion cooking [71] and by microwave-heating [72]. A similar trend to WAI was also observed for swelling power $(\mathrm{SP})$, indicating rather insignificant effects $(p>0.05)$ for the SP in all thermally stabilized $\mathrm{RB}$, compared with the untreated $\mathrm{RB}$; however, infrared radiation treatment increased significantly $(p<0.05)$ the SP of RB.

The foaming capacity (FC) and foaming stability (FS) of untreated and heat-stabilized RB samples are presented in Figure 3c. Generally, the RB has a low FC that may be associated with the presence of amphiphilic lipids in the $\mathrm{RB}$, since these are more easily adsorbed at the interface than proteins, influencing the strength and elasticity of the film and, therefore, its ability to incorporate air [73]. It is noticed that the heat stabilization of RB improved the FC compared to the untreated RB, particularly in the case of dry-heating and microwave treated samples; i.e., FC values were improved from $3.51 \%$ (untreated) to 5.70 and $7.92 \%$ after treatment by dry-heating and microwave-heating, respectively. Proteins also play a significant role in forming a stable air bubble because of their amphiphilic nature; i.e., the protein structure gets rapidly unfolded to form a cohesive macromolecular layer at the air-water interface [72]. Heat treatment could partially unfold the protein chains, making them easier to absorb at the air-water interface, and as a result, it leads to an increase in FC. Similarly, Rafe et al. [68] reported that extruded RB had a higher FC than unstabilized RB, and Zhu et al. [74] also found that the RB protein following high-pressure treatment enhanced its FC. Instead, Khan et al. [27] found that extended heat application impairs the foaming properties of protein products, whereas partial enzymatic hydrolysis improves the interfacial properties of these biomolecules. The decrease in the FC of the RB protein by infrared treatment might be due to its thermal denaturation, making the diffusion and adsorption of the protein components at the air-water interface more difficult [75]. FS refers to the ability to maintain the air bubble against breaking or collapsing. Similar to FC, FS increased with heat treatment following dry-heating and microwave-heating of the RB with an increase of 121 and $232 \%$, respectively, as compared with the untreated RB. However, there were no significant differences $(p>0.05)$ in the FS between untreated and stabilized RB by infrared-radiation. An improvement in FS might be related to enhanced protein-protein interactions (aggregation) upon heat treatment, bringing about a thick proteinaceous film around the air bubbles [76].

The emulsifying activity (EA) is mainly dependent on the diffusion of surface active constituents at the oil-water interfaces. The effect of heat stabilization of RB on EA and emulsion stability (ES) of RB is shown in Figure 3c. Dry-heating and infrared-radiation treatments of RB decreased the EA of RB $(p<0.05)$. Instead, microwave-heating treatment did not lead to significant changes in the EA of RB. The emulsions of all RB samples were very stable in the present study; the ES showed a similar trend among all samples to that of EA. In general, heating treatments decreased the surface activity and emulsion properties, which was probably due to protein denaturation in high temperatures [77]. 
Similar observations have been also reported by Capellini et al. [73] for rice bran defatted with alcoholic solvents.

\section{Conclusions}

The present study has demonstrated that infrared-radiation heating among other heat treatments such as dry-heating and microwave-heating could be an efficient method for inactivating lipase activity and prolonging the shelf-life of RB. It took a shorter processing time to effectively stabilize this dietary fiber source without affecting the nutritional profile, $\gamma$-oryzanol content, and ABTS radical scavenging activity while reducing the antinutrients and improving the ferric reducing antioxidant power. It also enhanced some functional properties (WSI and SP) of the heat-treated RB that may improve its use as a functional ingredient in food and cosmetics formulations. Instead, microwave stabilization was an effective treatment for improving the foaming and emulsifying capacities as well as water absorption of the RB. In addition, microwave treatment resulted in the largest reductions of antinutrients present in RB among all heat stabilization methods tested. Overall, among all studied methods, infrared-radiation heating appears a promising processing alternative to conventional dry-heating to stabilize $\mathrm{RB}$, provided that appropriate optimization studies will be undertaken to examine the impact of the various operation parameters and conditions on the physicochemical, bioactivity, and functional properties of this material at a commercial scale level.

Author Contributions: Conceptualization, M.I. and A.L.; methodology, M.I.; investigation, M.I.; resources, M I. and A.L.; data curation, M.I.; writing-original draft preparation, M.I.; writingreview and editing, A.L. and C.G.B.; supervision, C.G.B.; funding acquisition, A.L. All authors have read and agreed to the published version of the manuscript.

Funding: This research was funded by EYDE-ETAK through the Operational Program Competitiveness, Entrepreneurship and Innovation, which is co-financed by the European Union and Greek national funds, under the call RESEARCH-CREATE-INNOVATE, grant number T1EDK-01669 and the APC was funded by the same grant (T1EDK-01669).

Conflicts of Interest: The authors declare no conflict of interest.

\section{References}

1. Sharif, M.K.; Butt, M.S.; Anjum, F.M.; Khan, S.H. Rice bran: A novel functional ingredient. Crit. Rev. Food Sci. Nutr. 2014, 54, 807-816. [CrossRef]

2. Sohail, M.; Rakha, A.; Butt, M.S.; Iqbal, M.J.; Rashid, S. Rice bran nutraceutics: A comprehensive review. Crit. Rev. Food Sci. Nutr. 2017, 57, 3771-3780. [CrossRef]

3. Xu, Z.; Hua, N.; Godber, J.S. Antioxidant activity of tocopherols, tocotrienols, and $\gamma$-oryzanol components from rice bran against cholesterol oxidation accelerated by 2,20-azobis(2-methylpropionamidine) dihydrochloride. J. Agric. Food Chem. 2001, 49, $2077-2081$. [CrossRef] [PubMed]

4. Revilla, E.; Maria, C.S.; Miramontes, E.; Bautista, J.; Martínez, A.M.; Olga Cremades, O.; Cert, R.; Parrad, J. Nutraceutical composition, antioxidant activity and hypocholesterolemic effect of a water-soluble enzymatic extract from rice bran. Food Res. Intern. 2009, 42, 387-393. [CrossRef]

5. Debnath, T.; Park, S.R.; Kim, D.H.; Jo, J.E.; Lim, B.O. Anti-Oxidant and anti-inflammatory activities of inonotus obliquus and germinated brown rice extracts. Molecules 2013, 18, 9293-9304. [CrossRef] [PubMed]

6. Yasukawa, K.; Akihisa, T.; Kimura, Y.; Tamura, T.; Takido, M. Inhibitory effect of cycloartenyl ferulate, a component of rice bran, on tumor promotion in two stage carcinogenesis in mouse skin. Biol. Pharm. Bull. 1998, 21, 1072-1076. [CrossRef] [PubMed]

7. Ghatak, S.B.; Panchal, S.S. Anti-Diabetic activity of oryzanol and its relationship with the anti-oxidant property. Int. J. Diabetes Devel. Countr. 2012, 32, 185-192. [CrossRef]

8. Saunders, R.M. Rice bran: Composition and potential food uses. Food Rev. Int. 1985, 1, 465-495. [CrossRef]

9. Orthoefer, F.T. Rice bran oil: Healthy lipid source. Food Technol. 1996, 50, 62-64.

10. Thanonkaew, A.; Wongyai, S.; Mcclements, D.J.; Decker, E.A. Effect of stabilization of rice bran by domestic heating on mechanical extraction yield, quality, and antioxidant properties of cold-pressed rice bran oil (Oryza saltiva L.). LWT Food Sci. Technol. 2012, 48, 231-236. [CrossRef]

11. Kim, C.J.; Byun, S.M.; Cheigh, H.S.; Kwon, T.W. Optimization of extrusion rice bran stabilization process. J. Food Sci. 1987, 52, 1355-1357. [CrossRef] 
12. Patil, S.S.; Kar, A.; Mohapatra, D. Stabilization of rice bran using microwave: Process optimization and storage studies. Food Bioprod. Proces. 2016, 99, 204-211. [CrossRef]

13. Ramezanzadeh, F.M.; Rao, R.M.; Prinyawiwatkul, W.; Marshall, W.E.; Windhauser, M. Effects of microwave heat, packaging, and storagetemperature on fatty acid and proximate compositions in rice bran. J. Agric. Food Chem. 2000, 48, 464-467. [CrossRef] [PubMed]

14. Yilmaz, N.; Tuncel, B.N.; Kocabiyik, H. Infrared stabilization of rice bran and its effects on gamma-oryzanol content, tocopherols and fatty acid composition. J. Sci. Food Agric. 2014, 94, 1568-1576. [CrossRef]

15. Irakli, M.; Kleisiaris, F.; Mygdalia, A.; Katsantonis, D. Stabilization of rice bran and its effect on bioactive compounds content, antioxidant activity and storage stability during infrared radiation heating. J. Cereal Sci. 2018, 80, 135-142. [CrossRef]

16. Dhingra, D.; Chopra, S.; Rai, D.R. Stabilization of raw rice bran using ohmic heating. Agric. Res. 2012, 1, 392-398. [CrossRef]

17. Pradeep, P.M.; Jayadeep, A.; Guha, M.; Singh, V. Hydrothermal and biotechnological treatments on nutraceutical content and antioxidant activity of rice bran. J. Cereal Sci. 2014, 60, 187-192. [CrossRef]

18. Amarasinghe, B.M.W.P.K.; Kumarasiri, M.P.M.; Gangodavilage, N.C. Effect of method of stabilization on aqueous extraction of rice bran oil. Food Bioprod. Proces. 2009, 87, 108-114. [CrossRef]

19. Vallabha, V.S.; Indira, T.N.; Lakshmi, A.J.; Radha, C.; Tiku, P.K. Enzymatic process of rice bran: A stabilized functional food with nutraceuticals and nutrients. J. Food Sci. Techn. 2015, 52, 8252-8259. [CrossRef]

20. Gopinger, E.; Ziegler, V.; Catalan, A.A.D.S.; Krabbe, E.L.; Elias, M.C.; Xavier, E.G. Whole rice bran stabilization using a short chain organic acid mixture. J. Stored Prod. Res. 2015, 61, 108-113. [CrossRef]

21. Sharma, H.R.; Chauhan, G.S.; Agrawal, K. Physico-Chemical characteristics of rice bran processed by dry heating and extrusion cooking. Intern. J. Food Prop. 2004, 7, 603-614. [CrossRef]

22. Zigoneanu, I.G.; Williams, L.; Xu, Z.; Sabliov, C.M. Determination of antioxidant components in rice bran oil extracted by microwave-assisted method. Bioresour. Technol. 2008, 99, 4910-4918. [CrossRef] [PubMed]

23. Yan, W.; Liu, Q.; Wang, Y.; Tao, T.; Liu, B.; Liu, J.; Ding, C. Inhibition of lipid and aroma deterioration in rice bran by infrared heating. Food Bioproc. Technol. 2020, 13, 1677-1687. [CrossRef]

24. Riadh, M.H.; Ahmad, S.A.B.; Marhaban, M.H.; Soh, A.C. Infrared heating in food drying: An overview. Dry. Technol. 2015, $33,322-335$. [CrossRef]

25. Zhang, M.; Tang, I.; Mujumdar, A.S.; Wang, S. Trends in microwave related drying of fruits and vegetables. Trends Food Sci. Technol. 2006, 17, 524-534. [CrossRef]

26. Khan, S.H.; Butt, M.S.; Anjum, F.M.; Jamil, A. Antinutritional appraisal and protein extraction from differently stabilized rice bran. Pakistan J. Nutr. 2009, 8, 1281-1286. [CrossRef]

27. Khan, S.H.; Butt, M.S.; Sharif, M.K.; Sameen, A.; Mumtaz, S.; Sultan, M.T. Functional properties of protein isolates extracted from stabilized rice bran by microwave, dry heat, and parboiling. J. Agric. Food Chem. 2011, 59, 2416-2420. [CrossRef]

28. Yueh, J.Y.; Phillips, R.D.; Resurreccion, A.V.A.; Hung, Y.C. Physicochemical and sensory characteristic changes in fortified peanut spreads after 3 months of storage at different temperatures. J. Agric. Food Chem. 2002, 50, 2377-2384. [CrossRef]

29. AOAC. International Official Methods of Analysis, 20th ed.; Association of Official Agricultural Chemists: Rockville, MD, USA, 2016.

30. AOAC Method 996-06. Fats (total, saturated and unsaturated) in foods. In AOAC Official Methods of Analysis; Association of Official Analytical Chemists Inc.: Gaithersburg, MD, USA, 2002.

31. AACC. Method 02-01 Fat acidity-General method. In Approved Methods of Analysis; AACC International: St. Paul, MN, USA, 2000.

32. Rose, D.J.; Pike, O.A. A simple method to measure lipase activity in wheat and wheat bran as an estimation of storage quality. J. Am. Oil Chem. Soc. 2006, 83, 415-419. [CrossRef]

33. Singleton, V.L.; Orthofer, R.; Lamuela-Raventos, R.M. Analysis of total phenols and other oxidation substrates and antioxidants by means of Folin-Ciocalteu reagents. Methods Enzymol. 1999, 299, 152-178.

34. Irakli, M.; Chatzopoulou, P.; Kadoglidou, K.; Tsivelika, N. Optimization and development of a high-performance liquid chromatography method for the simultaneous determination of vitamin E and carotenoids in tomato fruits. J. Sep. Sci. 2016, 39, 3348-3356. [CrossRef] [PubMed]

35. Fang, N.; Yu, S.; Badger, T.M. Characterization of triterpene alcohol and sterol ferulates in rice bran using LC-MS/MS. J. Agric. Food Chem. 2003, 51, 3260-3267. [CrossRef] [PubMed]

36. Oyeyinka, B.O.; Afolayan, A.J. Comparative evaluation of the nutritive, mineral, and antinutritive composition of musa sinensis 1. (banana) and musa paradisiaca 1. (plantain) fruit compartments. Plants 2019, 8, 598. [CrossRef] [PubMed]

37. Wheeler, E.L.; Ferrel, R.E. A method for phytic acid determination in wheat and wheat products. Cereal Chem. 1971, 48, 312-320.

38. Hierro, J.N.; Herrera, T.; García-Risco, M.R.; Fornari, T.; Reglero, G.; Martina, D. Ultrasound-Assisted extraction and bioaccessibility of saponins from edible seeds: Quinoa, lentil, fenugreek, soybean and lupin. Food Res. Intern. 2018, 109, 440-447. [CrossRef] [PubMed]

39. Kakade, M.L.; Rackis, J.J.; McGhee, J.E.; Puski, G. Determination of trypsin inhibitor activity of soy products: A collaborative analysis of an improved procedure. Cereal Chem. 1974, 51, 376-381.

40. Makkar, H.P.S.; Bluemmel, M.; Borowy, N.K.; Becker, K. Gravimetric determination of tannins and their correlation with chemical and protein precipitation method. J. Sci. Food Agric. 1993, 61, 161-165. [CrossRef]

41. Re, R.; Pellegrini, N.; Proteggente, A.; Pannala, A.; Yang, M.; Rice-Evans, C.A. Antioxidant activity applying an improved ABTS radical cation decolorization assay. Free Rad. Biol. Med. 1999, 26, 1231-1237. [CrossRef] 
42. Yen, G.C.; Chen, H.Y. Antioxidant activity of various tea extracts in relation to their antimutagenicity. J. Agric. Food Chem. 1995, 43, 27-32. [CrossRef]

43. Benzie, F.; Strain, J. Ferric reducing/antioxidant power assay: Direct measure of total antioxidant activity of biological fluids and modified version for simultaneous measurement of total antioxidant power and ascorbic acid concentration. Methods Enzymol. 1999, 299, 15-23.

44. Kaushala, P.; Kumara, V.; Sharma, H.K. Comparative study of physicochemical, functional, antinutritional and pasting properties of taro (Colocasia esculenta), rice (Oryza sativa) flour, pigeonpea (Cajanus cajan) flour and their blends. LWT Food Sci. Techn. 2012, 48, 59-68. [CrossRef]

45. Abebe, W.; Collar, C.; Ronda, F. Impact of variety type and particle size distribution on starch enzymatic hydrolysis and functional properties of tef flours. Carbohydr. Polym. 2015, 115, 260-268. [CrossRef] [PubMed]

46. Nazck, M.; Diosady, L.L.; Rubin, L.J. Functional properties of canola meals produced by two-phase solvent extraction systems. J. Food Sci. 1985, 50, 1685-1692.

47. Yu, C.W.; Hu, Q.R.; Wang, H.W.; Deng, Z.Y. Comparison of 11 rice bran stabilization methods by analyzing lipase activities. J. Food Process. Preserv. 2020, 44, 14370-14384. [CrossRef]

48. Oliveira, M.S.; Feddern, V.; Kupski, L.; Cipolatti, E.P.; Badiale-Furlong, E.; Souza-Soares, L.A. Changes in lipid, fatty acids and phospholipids composition of whole rice bran after solid-state fungal fermentation. Bioresource Technol. 2011, 102, 8335-8338. [CrossRef] [PubMed]

49. Martin, C.A.; Almeida, V.V.; Ruiz, M.R.; Visentainer, J.E.L.; Matshushita, M.; Souza, N.E.; Visentainer, J.V. Omega-3 and omega-6 polyunsaturated fatty acids: Importance and occurrence in foods. Rev. Nutr. 2006, 19, 761-770. [CrossRef]

50. Rodchuajeen, K.; Niamnuy, C.; Charunuch, C.; Soponronnarit, S.; Devahastin, S. Stabilization of rice bran via different moving-bed drying methods. Drying Technol. 2016, 34, 1854-1867. [CrossRef]

51. Oatway, L.; Vasanthan, T.; Helm, J.H. Phytic acid. Food Rev. Int. 2001, 17, 419-431. [CrossRef]

52. Kaur, S.; Sharma, S.S.; Singh, B.; Dar, B.N. Effect of extrusion variables (temperature, moisture) on the antinutrient components of cereal brans. J. Food Sci. Technol. 2015, 52, 1670-1676. [CrossRef]

53. Kakati, P.; Deka, S.; Kotoki, D.; Saikia, S. Effect of traditional methods of processing on the nutrient contents and some antinutritional factors in newly developed cultivars of green gram [Vigna radiata (L.) Wilezek] and black gram [Vigna mungo (L.) Hepper] of Assam, India. Intern. Food Res. J. 2010, 17, 377-384.

54. Savage, G.P.; Vanhanen, L.; Mason, S.M.; Rose, A.B. Effect of cooking on the soluble and insoluble oxalate content of some New Zealand foods. J. Food Comp. Anal. 2000, 13, 201-206. [CrossRef]

55. Morozumi, M.; Ogawa, Y. Impact of dietary calcium and oxalate ratio on urinary stone formation in rats. Mol. Urol. 2000, 4, 313-320. [PubMed]

56. Embaby, H.E. Effect of soaking, dehulling, and cooking methods on certain antinutrients and in vitro protein digestibility of bitter and sweet lupin seeds. Food Sci. Biotechnol. 2010, 19, 1055-1062. [CrossRef]

57. Bissinger, R.; Modicano, P.; Alzoubi, K.; Honisch, S.; Faggio, C.; Abed, M.; Lang, F. Effect of saponin on erythrocytes. Int. J. Hematol. 2014, 100, 51-59. [CrossRef] [PubMed]

58. Serrano, J.; Puupponen-Pimiä, R.; Dauer, A.; Aura, A.M.; Saura-Calixto, F. Tannins: Current knowledge of food sources, intake, bioavailability and biological effects. Mol. Nutr. Food Res. 2009, 53, S310-S329. [CrossRef]

59. Sahni, P.; Sharma, S. Influence of processing treatments on cooking quality, functional properties, antinutrients, bioactive potential and mineral profile of alfalfa. LWT Food Sci. Technol. 2020, 132, 109890. [CrossRef]

60. Osman, M.A. Effect of different processing methods on nutrient composition, antinutritional factors, and in vitro protein digestibility of dolichos lablab beans (LabLab purpuresus (L) sweet). Pakistan J. Nutr. 2007, 6, 299-303. [CrossRef]

61. Deng, Y.; Padilla-Zakour, O.; Zhao, Y.; Tao, S. Influences of high hydrostatic pressure, microwave heating, and boiling on chemical compositions, antinutritional factors, fatty acids, in vitro protein digestibility, and microstructure of buckwheat. Food Bioprocess. Technol. 2015, 8, 2235-2245. [CrossRef]

62. Saji, N.; Schwarz, L.J.; Santhakumar, A.B.; Blanchard, C.L. Stabilization treatment of rice bran alters phenolic content and antioxidant activity. Cereal Chem. 2020, 97, 281-292. [CrossRef]

63. Laokuldilok, T.; Rattanathanan, Y. Protease treatment for the stabilization of rice bran: Effects on lipase activity, antioxidants, and lipid stability. Cereal Chem. 2014, 91, 560-565. [CrossRef]

64. Lakkakula, N.R.; Lima, M.; Walker, T. Rice bran stabilization and rice bran oil extraction using ohmic heating. Bioresour. Technol. 2004, 92, 157-161. [CrossRef] [PubMed]

65. Yeo, J.; Shahidi, F. Effect of hydrothermal processing on changes of insoluble-bound phenolics of lentils. J. Funct. Foods 2017, 38, 716-722. [CrossRef]

66. Miranda, M.; Maureira, H.; Rodriguez, K.; Vega-Galvez, A. Influence of temperature on the drying kinetics, physicochemical properties, and antioxidant capacity of Aloe Vera (Aloe Barbadensis Miller) gel. J. Food Eng. 2009, 91, 297-304. [CrossRef]

67. Daou, C.; Zhang, H. Study on functional properties of physically modified dietary fibres derived from defatted rice bran. J. Agric. Sci. 2012, 4, 85-97. [CrossRef]

68. Rafe, A.; Sadeghian, A.; Hoseini-Yazdi, S.Z. Physicochemical, functional, and nutritional characteristics of stabilized rice bran form tarom cultivar. Food Sci. Nutri. 2017, 5, 407-414. [CrossRef]

69. Britten, L.L.M. Foaming properties of proteins as affected by concentration. J. Food Sci. 1992, 57, 1219-1241. [CrossRef] 
70. Tang, S.; Hettiarachchy, N.S.; Horax, R.; Eswaranandam, S. Physicochemical properties and functionality of rice bran protein hydrolyzate prepared from heat-stabilized defatted rice bran with the aid of enzymes. J. Food Sci. 2003, 68, 152-157. [CrossRef]

71. Sharma, R.; Srivastava, T.; Saxena, D.C. Valorization of deoiled rice bran by development and process optimization of extrudates. Engineer. Agric. Envi. Food 2019, 12, 173-180. [CrossRef]

72. Villanueva, M.; Lamo, B.D.; Harasyma, J.; Ronda, R. Microwave radiation and protein addition modulate hydration, pasting and gel rheological characteristics of rice and potato starches. Carboh. Polym. 2018, 201, 374-381. [CrossRef]

73. Capellinia, M.C.; Novais, J.S.; Monteiro, R.F.; Veiga, B.Q.; Osiro, D.; Rodrigues, C.E.C. Thermal, structural and functional properties of rice bran defatted with alcoholic solvents. J. Cereal Sci. 2020, 95, 103067. [CrossRef]

74. Zhu, S.M.; Lin, L.; Ramaswamy, H.S.; Yu, Y.; Zhang, Q.T. Enhancement of functional properties of rice bran proteins by high pressure treatment and their correlation with surface hydrophobicity. Food Bioprocess. Technol. 2017, 10, 317-327. [CrossRef]

75. LV, S.H.; He, L.Y.; Sun, L.H. Effect of different stabilisation treatments on preparation and functional properties of rice bran proteins. Czech J. Food Sci. 2018, 36, 57-65. [CrossRef]

76. Andersen, O.S.; Fuchs, M. Preparation and some functional properties of rice bran protein concentrate at different degree of hydrolysis using bromelain and alkaline extraction. Prepar. Biochem. Biotechnol. 2009, 39, 183-193.

77. Zhang, Y.; Wang, B.; Zhang, W.; Xu, W.; Hu, Z. Effects and mechanism of dilute acid soaking with ultrasound pretreatment on rice bran protein extraction. J. Cereal Sci. 2019, 87, 318-324. [CrossRef] 